\title{
The Effect of Mesenchymal Stem Cell-Enriched Scaffolds on MMP-8 and TGF- $\beta$ Levels of Vertebrae Postlaminoplasty in Rabbit Model
}

\author{
Ahmad Jabir Rahyussalim (D) \\ Roni Eka Sahputra \\ Yanwirasti \\ Menkher Manjas \\ Yudan Whulanza \\ Tri Kurniawati \\ Dina Aprilya (iD) \\ Muhammad Luqman Labib Zufar (D) \\ 'Department of Orthopedics and \\ Traumatology Clinics, Faculty of \\ Medicine, Universitas of Indonesia-Cipto \\ Mangunkusumo General Hospital, \\ Jakarta, Indonesia; ${ }^{2}$ Stem Cell and Tissue \\ Engineering Cluster, IMERI Faculty of \\ Medicine, Universitas Indonesia, Jakarta, \\ Indonesia; ${ }^{3}$ Stem Cell Medical Technology \\ Integrated Service Unit, Cipto \\ Mangunkusumo General Hospital, \\ Jakarta, Indonesia; ${ }^{4}$ Department of \\ Surgery, Faculty of Medicine, Universitas \\ Andalas-RSUP M. Djamil, Padang, \\ Indonesia; ${ }^{5}$ Department of Anatomy, \\ Faculty of Medicine, Universitas Andalas- \\ RSUP M. Djamil, Padang, Indonesia; \\ ${ }^{6}$ Department of Mechanical Engineering, \\ Faculty of Engineering, Universitas \\ Indonesia, Jakarta, Indonesia
}

Introduction: Some laminoplasty procedures still have restenosis because of bony-bridging failure of the laminar hinge. The present study aimed to determine the effect of mesenchymal stem cell (MSC)-enriched scaffolds on vertebral regeneration after laminoplasty on the basis of the number of osteoblasts, matrix metalloproteinase-8 (MMP-8), and transforming growth factor-beta (TGF- $\beta$ ) levels.

Methods: Laminoplasty procedure using the Hirabayashi technique was conducted at the lumbar level in 32 rabbits that were divided into four and three groups of the control $(\mathrm{C})$ and treatment groups, respectively, with different types of laminoplasty spacer (T1, autograft; T2, scaffold; and T3, scaffold with MSCs). Histopathological studies were conducted to calculate the number of osteoblasts and enzyme-linked immunosorbent assay tests to detect MMP-8 and TGF- $\beta 4$ weeks after the surgery.

Results: The results showed a significant decrease in MMP-8 level in the T3 group compared with that in the control group $(\mathrm{p}<0.05)$. A significant difference exists between the average number of newly formed osteoblasts in the control group compared with that in the T3 group $(\mathrm{p}<0.05)$ with a higher mean blood TGF- $\beta$ level of all experimental groups compared with that of the control group $(\mathrm{p}=0.58)$.

Conclusion: The significant decrease in MMP- 8 levels, increase in TGF- $\beta$ levels, and increased number of osteoblasts on MSC-seeded polylactic acid scaffolds could be useful to support the laminoplasty procedure to prevent restenosis because it was biocompatible and promoted the bone healing process.

Keywords: laminoplasty, Hirabayashi technique, mesenchymal stem cells, scaffolds

\section{Introduction}

Spinal stenosis is the most common example of degenerative processes that occur in the spine. ${ }^{1,2}$ Various methods of decompressing the nerve roots have been attempted with both anterior and posterior approaches. Decompression can be achieved in multiple stenosis cases while maintaining neck movements by laminoplasty technique. ${ }^{2,3}$ Moreover, decompression is achieved by lifting the lamina on one side which helps widen the canal maintained by the spacer. ${ }^{3-5}$

Several types of scaffold materials used for laminoplasty spacer have been widely studied (eg, hydroxyapatite [HA], polymers, and ceramic and polymer composites) along with natural polymers (eg, collagen and chitin). ${ }^{6-8}$ Polylactic acid (PLA) is one of the extensively used biomaterials in orthopedic applications because of its availability, easier processability, and low toxicity to living cells. ${ }^{9,10}$
Labib Zufar

Department of Orthopedics and

Traumatology Clinics, Faculty of Medicine

Universitas of Indonesia-Cipto

Mangunkusumo General Hospital, Jakarta,

10430, Indonesia

Tel +6281385287727

Email muhammad.luqman4I@ui.ac.id 


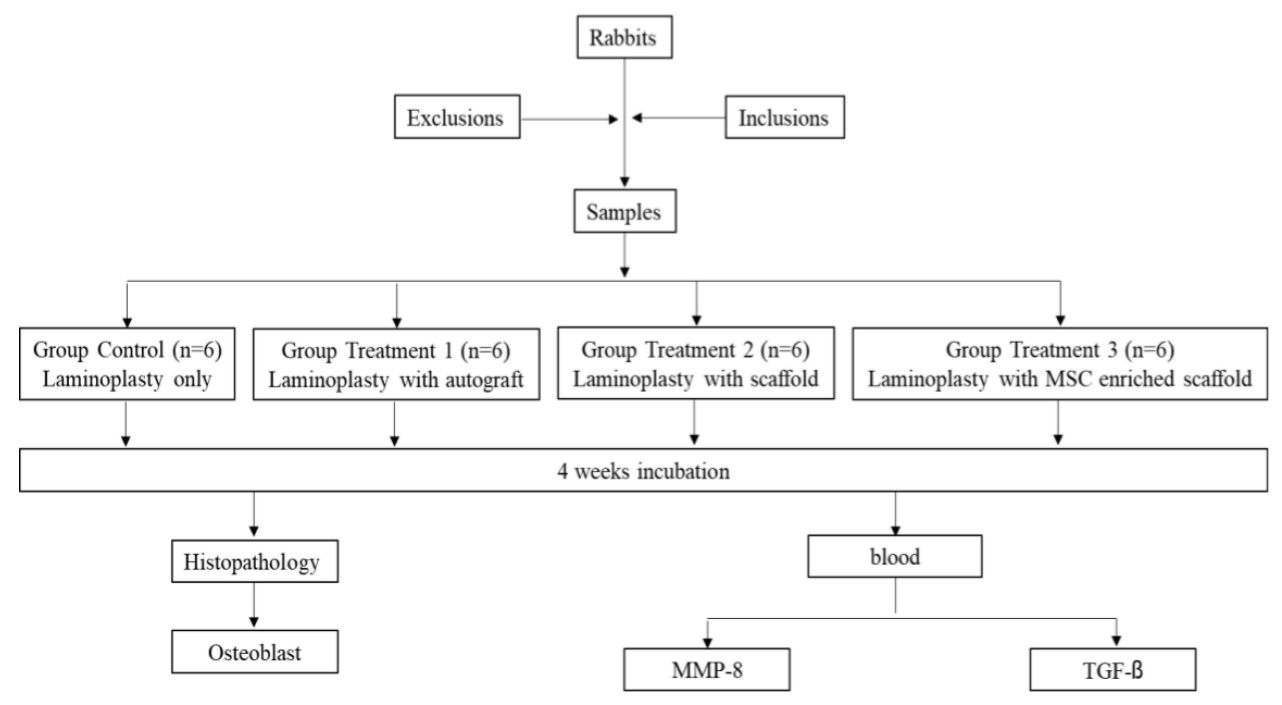

Figure I Algorithm of the research steps.

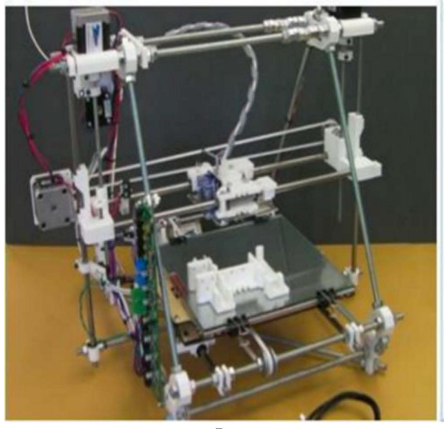

A
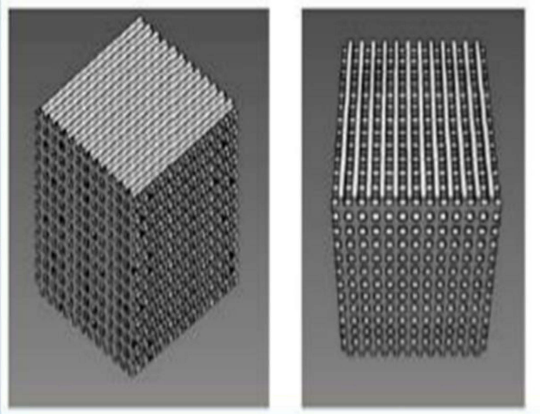

B

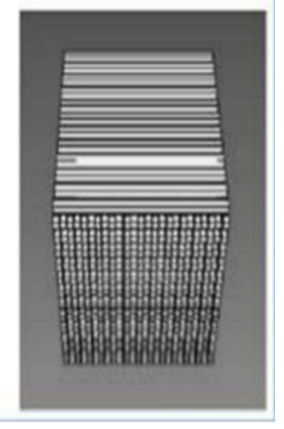

Figure 2 (A) Fused Deposition Modeling Mono Mendel; (B) design of 3D-printed scaffold fabricated through PLA deposition modeling.

However, not much literature exists to examine the effectivity of scaffold materials used as spacers along with the use of mesenchymal stem cells (MSCs) as an osteoinductive substance in laminoplasty procedures.

This study aims to demonstrate the potential effects of MSC-seeded PLA scaffolds on bone formation in a rabbit model of vertebrae laminoplasty using the Hirabayashi technique by evaluating matrix metalloproteinase (MMP) and transforming growth factorbeta (TGF- $\beta$ ) activities. Both can be used as markers for bone regeneration and immune responses from the body. MMP-8 has functions in initiating collagen degradation in extracellular matrix during embryogenesis, bone healing, and bone regeneration and reflecting inflammatory response in the initial wound repair stage because of its high-level expression from neutrophils. ${ }^{11-15}$ Moreover, TGF- $\beta$ has been widely accepted for its roles in bone formation and regeneration in the mammalian model. Furthermore, TGF- $\beta$ increases in a substantial value during proliferation and differentiation of MSCs toward osteoblastic lineage. ${ }^{16,17}$

\section{Materials and Methods Ethics Statement}

This was an interventional study using an animal model. The research protocol was reviewed and approved by the Research Ethical Committee of the Medical Research Unit (FMUI-RSCM No. 631/UN2.F1/ETIK/PPM.00.02/2019) and the Committee of the Research Ethics of the Faculty of Medicine, Andalas University (No. 204/KEP/FK/2019) in accordance with the Government of Republic of Indonesia's Regulation No. 95. 2012 (Veterinary Public Health and Animal Welfare) and the National Guidelines 


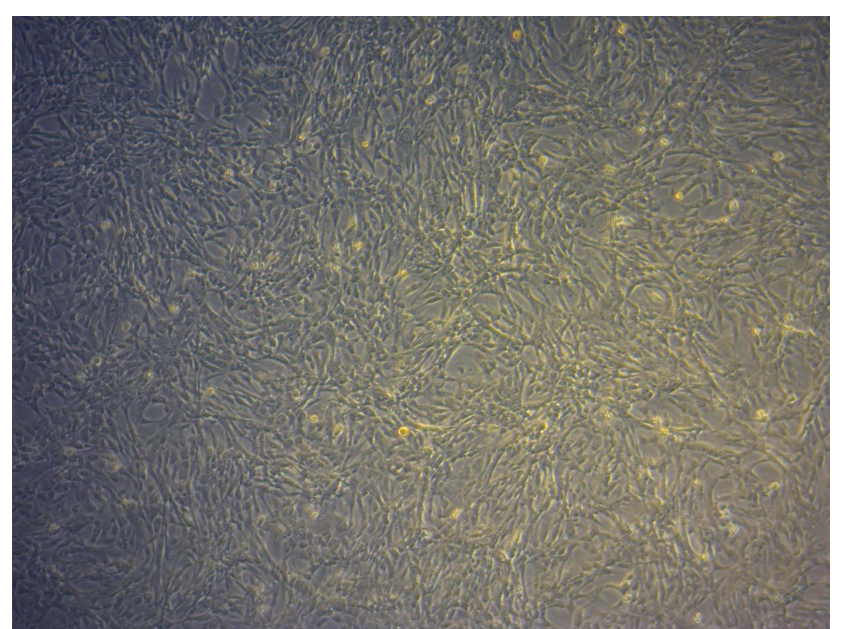

Figure 3 Cell culture of UCMSCs (Culture day $5^{\text {th }}$, passage 4, magnification 40x).

on Health Research Ethics by Health Research Ethics Committee, the Ministry of Health, Republic of Indonesia, as the guidelines followed for the welfare and treatment of the laboratory animals. In addition, the donors of the UC-MSCs had provided informed consent, in accordance with the Declaration of Helsinki. The authors did not have any conflict of interest.

\section{Animals}

The selection of rabbit samples was handled by a Laboratory Animal Basic Training (in-house)-certified veterinarian and more than 10 years working with laboratory animals. The selection was based on the rabbit's body weight; bone maturity; and clinical, radiological, and laboratory examination. The inclusion criteria were white rabbits of New Zealand strains weighing 1500-2500 g, which were healthy and skeletally mature. Conversely, the exclusion criteria were rabbits with congenital spine abnormalities and/or abnormalities in the spine caused by infections, trauma, neoplasm, and so on. Antibiotics, enrofloxacin (5-10 mg/kg subcutis), were immediately given before surgery.

\section{Experimental Design}

The sample size in this study, according to Federer's formula, was 24 rabbits divided into four groups (six rabbits in each group). The first group (group C) was the laminoplasty-only group; the second group (T1) included the rabbits who had undergone laminoplasty with autograft implantation; the third group (T2) consisted of the rabbits that had undergone laminoplasty with a scaffold without MSCs; and the last group (T3) consisted of the rabbits that had undergone laminoplasty with MSC-enriched scaffold implantation. The rabbits were euthanized at the end of week 4, and blood samples were taken for MMP-8 and TGF- $\beta$ test. Although spinal fusion in animal studies was commonly seen in 6-10 weeks, the cutoff of 4 weeks in this model was based on the expected faster healing induced by osteoinductive and osteoconductive materials used. Necropsy was then performed on the rabbit, and lesion tissue was taken for histopathology staining (Figure 1).

\section{Mesenchymal Stem Cell-Enriched Scaffolds Preparation}

The scaffolds were developed in the Mechanical Engineering Laboratory. Fused Deposition Modeling Mono Mendel was used to produce the scaffolds (Figure 2A). Moreover, PLA was used as a biomaterial because of its availability, easier processability, and low toxicity to living cells. The scaffold's construct was developed with geometry quadrilaterals (Figure 2B) which produced the final four-layered scaffold with a dimension of $0.41 \pm 0.01 \mathrm{~mm}^{2}$ with $59-80 \%$ porosity. Before coculture, scaffolds were sterilized in a $70 \mathrm{~mL}$ alcohol solution for 20 $\min$ in a $1.5 \mathrm{~mL}$ tube. Scaffolds were then rinsed with sterile bidestilate water and filtered with a $0.22 \mu \mathrm{M}$ filter two to three times for as much as $400-500 \mathrm{~mL}$. They were then placed in a plate culture container filled with cells.

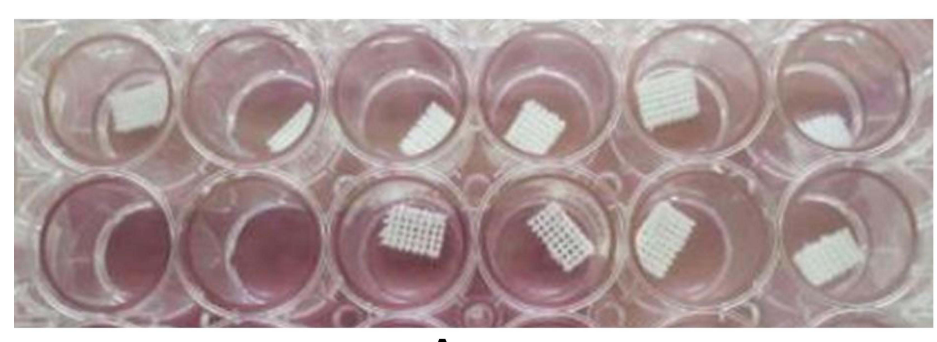

A

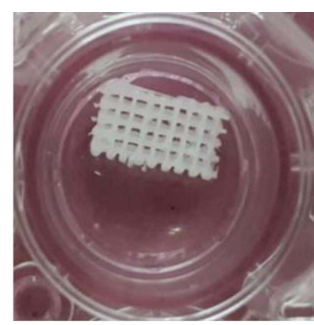

B

Figure 4 (A) Mesenchymal stem cells were seeded into the scaffold; (B) mesenchymal stem cells are ready to be implanted into the scaffold. 
Human umbilical cord mesenchymal stem cells (UCMSCs) were cultured in growing media and then isolated by the multiple harvests explant method, cryopreserved, and stored in liquid nitrogen. The sample was obtained from the Stem Cell Medical Technology Integrated Service Unit, Cipto Mangunkusumo General Hospital. Cryopreserved UC-MSCs were rapidly thawed and recultured in a $25 \mathrm{~cm}^{2}$ tissue culture (T25) flask in $10 \%$ platelet lysate containing complete medium (Figure 3 ). The cells were harvested, counted, and immediately implanted into the scaffold at $80-90 \%$ confluence. Ten scaffolds were placed into wells (Figure 4A and B). Two wells were filled only by cells and used as controls. The scaffold was placed into the well before adding the cells and the medium to prevent the scaffold from floating. Thus, cells that tend to attach to the bottom of the wells to reach all parts of the prepared scaffold were enabled. During the 4-day incubation period, $500 \mu \mathrm{L}$ of the medium was added for cell nutrition every day for three consecutive days.

The number of growing stem cells on the scaffold was calculated using the trypan blue method, which has long been the gold standard for dead cell staining. Viable cells present in cell suspension excluded the trypan blue dyes, whereas dead cells do not. ${ }^{18}$ The final value of this method is the number of viable cells per milliliter in the original cell suspension and the viability percentage, which is counted by dividing the live cell count by the total cell count. The saturation method of cell suspension with additional incubation was used to increase seeding efficiency to prevent cell detachment and death during the seeding period.

\section{Laminoplasty Procedures}

The laminoplasty procedure using the Hirabayashi technique was conducted on the lumbar vertebrae of the rabbits (Figure 5). Rabbits were prepared and draped with the standard sterile procedure and placed in a prone position under general anesthesia using ketamine $(44 \mathrm{mg} / \mathrm{kg})$. Each midline longitudinal posterior incision was performed for approximately $4 \mathrm{~cm}$. Deep dissection was performed to expose the spinous process of three levels of lumbar vertebrae along with the laminae. Spinous processes were removed, and the lamina was thinned to the lamina-facet junction. Finally, a lateral hinge was made on one side of the lamina using a high-speed burr, and it was elevated and secured in an open position using spacers.

Autografts were used as spacers, along with a bone that was available from the excision of the spinous processes.
The scaffolds, either with or without MSCs, were placed to support the elevated lamina. The surgical wound was then covered by bandages, and the rabbits were returned to their cage and observed until they recovered from anesthesia. Isotonic $\mathrm{NaCl}$ was infused subcutaneously and ketoprofen $(3 \mathrm{mg} / \mathrm{kg}$ ) intramuscularly every $12 \mathrm{~h}$ for 3 days. Rabbits were then held individually in cages for 4 weeks.

Rabbits were sacrificed by cervical dislocation 4 weeks after the surgery, and their vertebral column bones were retrieved to include one level above and one level below the treated vertebra. Specimens were prepared for histopathological examination by rapid bone decalcifier and then stained with hematoxylin and eosin (H\&E) staining available in the institution. Scaffolds were not dissolved from the samples before paraffin embedding. The effect of osteoblasts addition was compared after conducting osteoblast staining. Osteoblasts were counted by counting the number of cells five times the field of view and then averaging them. Tissue reactions in the presence of increased osteoblasts could be a parameter, indicating the success of this study.

Blood samples taken from the rabbits were centrifuged, and serum was obtained. The serum was placed in the refrigerator at $-40^{\circ} \mathrm{C}$. The MMP- 8 and TGF- $\beta$ levels were subsequently calculated. Enzyme-linked immunosorbent assay tests were conducted to detect matrix MMP-8 and TGF- $\beta$. MMP- 8 represents the increase of inflammatory processes that could happen in the early healing process. However, it can also increase in prolonged inflammatory reaction (eg, infection or allergic reaction). Moreover, TGF- $\beta$ represents the anabolic metabolism and positive effect of the bone healing process. TGF- $\beta$ is produced by osteoblastic lineage cells. They also give positive feedback to the MSC recruitment and osteoblast differentiation for new bone formation. Therefore, the addition of mesenchymal cell into the scaffold is postulated to cause an increase in TGF- $\beta$, which subsequently increase osteogenesis.

This study only measured the biomarkers in the blood and not in the local tissue because this method was found to be more comfortable for use and it has proven that both markers can be systemically found during the bone healing process. Radiographic modality (eg, CT scan) was also not used to evaluate fusion because of limited animal laboratory facilities in the institution. The Shapiro-Wilk test was conducted to view the normal distribution data, and normally distributed data were analyzed with the analysis of variance to determine differences in the average levels of TGF- $\beta$ and 


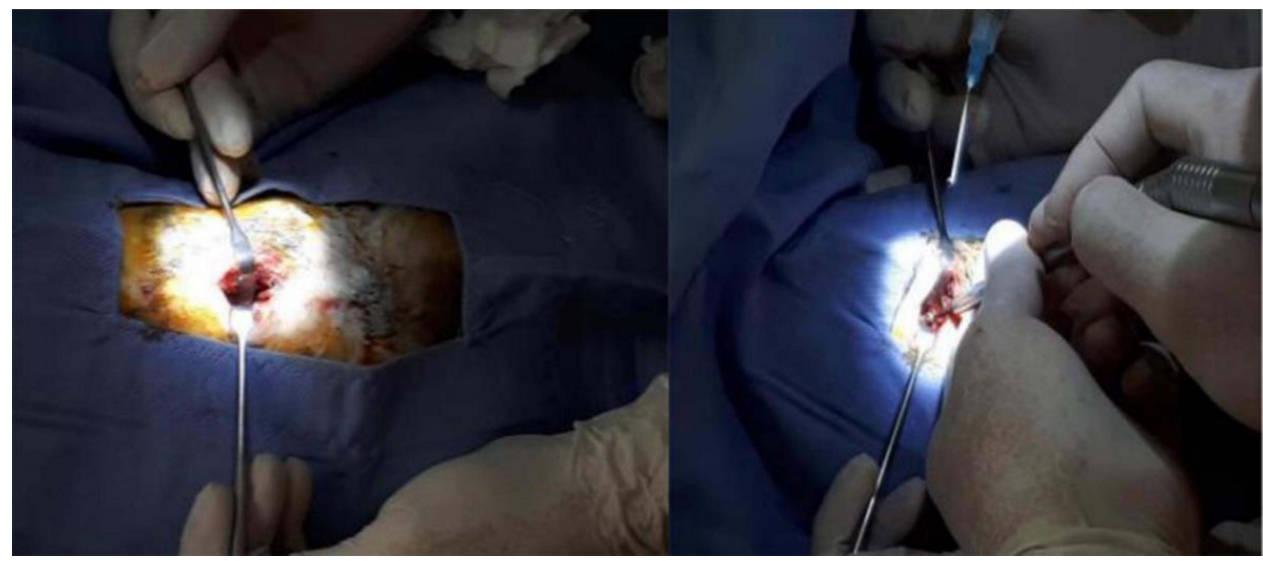

Figure 5 Laminoplasty procedure using the Hirabayashi technique was conducted on the lumbar vertebrae in rabbits.

MMP-8. Moreover, the post hoc Bonferroni test was applied if statistically significant results were obtained.

\section{Results}

\section{Clinical Signs}

In the 4 weeks of follow-up, two rabbits were paralyzed (T1 and T3), one rabbit expired (group C), and one rabbit had an infection of the white nodules under the skin (T2).

\section{Mesenchymal Stem Cell-Enriched Scaffolds}

Sixteen scaffolds were prepared for the two groups with eight scaffolds in each group (T2 and T3 groups). The T3 group consisted of the MSC-seeded scaffold.

MSCs that were entrapped within scaffolds were counted (Table 1), and the MSC-seeded process of the scaffold was described. The number of MSCs attached to the scaffold were $0.07 \times 10^{6}$ (lowest; scaffold B3 and B4) and $2.14 \times 10^{6}$ (highest; scaffold B1).

Table I Number of Mesenchymal Stem Cells Entrapped within the Scaffolds

\begin{tabular}{|l|l|}
\hline Subject & Total Cells (Cells/mL) \\
\hline A1 (Scaffold I) & $0.83 \times 10^{6}$ \\
A2 (Scaffold 2) & $0.89 \times 10^{6}$ \\
A3 (Scaffold 3) & $0.53 \times 10^{6}$ \\
A4 (Scaffold 4) & $1.41 \times 10^{6}$ \\
A5 (Scaffold 5) & $1.07 \times 10^{6}$ \\
A6 (Scaffold 6) & $1.08 \times 10^{6}$ \\
BI (Scaffold 7) & $2.14 \times 10^{6}$ \\
B2 (Scaffold 8) & $1.56 \times 10^{6}$ \\
B3 (Scaffold 9) & $0.07 \times 10^{6}$ \\
B4 (Scaffold 10) & $0.07 \times 10^{6}$ \\
\hline
\end{tabular}

\section{Macroscopic Lesion and Tissue Reaction}

The tissue reaction in groups $\mathrm{C}$ and $\mathrm{T} 1$ showed the formation of a thick, soft tissue at the implantation site. Additionally, a bony bridge formation in the T3 was thicker compared to the T2. The fine motion of the incorporation was checked by manual palpation of the scaffolds in group T3 (Figure 6). It was felt to be strongly fixed, whereas the scaffolds in group T2 were weakly fixed. This indicates that the osteogenesis was more advanced in group T3 where the scaffolds were planted with MSCs.

\section{Histopathological Examinations}

Histopathological tests were conducted using H\&E staining (Figure 7). The tissue reactions were evident from the increase in the number of osteocytes and osteoblasts. The osteoblasts of each group were counted and compared. The cell counts were done by counting the total amount of cells on five visual fields and then averagi ng them. The challenges were in determining the scaffolds on such a small tissue slice of $0.3-0.5 \mathrm{~mm}$. In a larger slice, scaffolds were detached from the surrounding tissue. Therefore, the scaffolds could not be seen. However, an increase in osteoblast count in group T3 indicates that mesenchymal-rich scaffolds have a positive impact on osteogenesis.

\section{Effect of MSC-Enriched Scaffolds Application in Laminoplasty Procedure to Blood MMP-8 Level}

The mean blood MMP-8 level for each group showed that the mean blood MMP-8 level in groups T1 and T3 was lower than that in group $\mathrm{C}$, whereas the mean of blood MMP-8 level in group T2 was higher than that in group C (Table 2). 

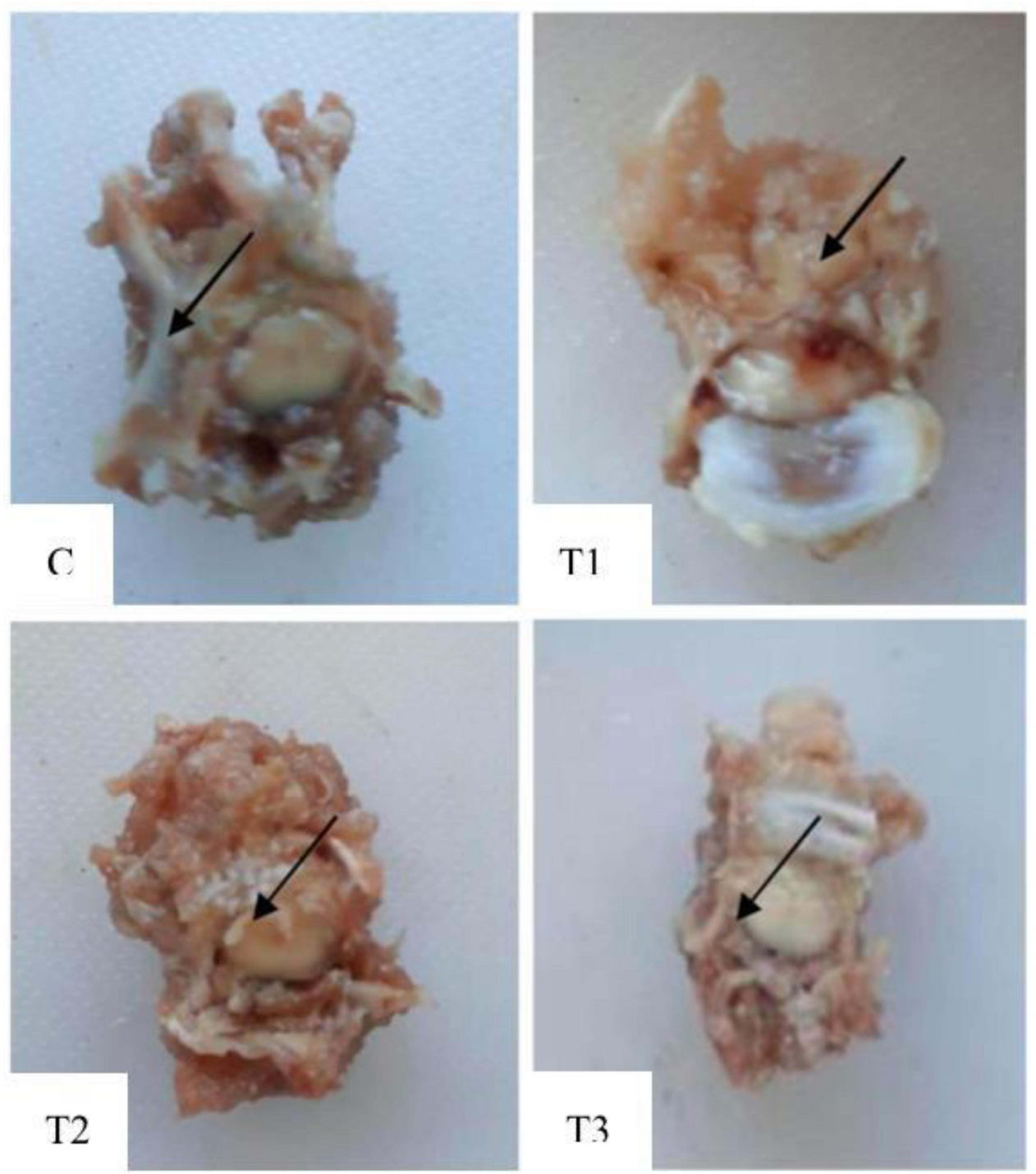

Figure 6 Macroscopic appearance showed the variable amount of new bone formation. In the control and TI groups, a thick granulation tissue exists without a clear laminoplasty defect. In the T2 group, scaffolds were well-embedded on the laminoplasty defect. Thicker bony bridge formation was found at the site of implantation compared with that in the T2 group.

A decrease in blood MMP-8 level was noted in group $\mathrm{T} 3$ compared with that in group $\mathrm{C}(\mathrm{p}<0.05)$. By contrast, the MMP-8 level of group T2, which was not enriched by MSCs, significantly increased compared with that of group $\mathrm{C}(\mathrm{p}<0.05)$. The use of autograft spacer from a spinous process showed the suppression of the blood MMP-8 level although not statistically significant $(\mathrm{p}=0.194)$.

\section{Effect of MSC-Enriched Scaffolds} Application in Laminoplasty Procedure to Blood TGF- $\beta$ Level

The mean blood TGF- $\beta$ level in all experimental groups was higher compared with that in the control group $(\mathrm{p}=$
0.58; Table 3). Although no statistical difference was noted on the TGF- $\beta$ level between the experimental and control groups, the T3 group had the least rate of increase among the experimental group. This result showed that MSCs may play a role in controlling the cell environment that contributes to TGF- $\beta$ expression.

\section{Effect of MSC-Enriched Scaffolds Application in Laminoplasty Procedure to Osteoblast Cell Count}

The mean number of osteoblasts in each experimental group was higher than that in the control group with group T3 having the highest value (Table 4). The mean 
of the osteoblast number was higher in the T3 group than that in the control $(\mathrm{p}<0.05), \mathrm{T} 2(\mathrm{p}=1.00)$, and $\mathrm{T} 1$ ( $\mathrm{p}=$ $1.00)$ groups. This showed that MSCs play roles in new bone formation to allow a bony bridge to fill the defect or bone gap.

\section{Discussion}

The expansive laminoplasty procedure used for posterior spinal decompression will cause vertebral bone defects in the posterior vertebral arch and increase the risk of postoperative development of instability, cervical kyphosis, or further neurological deterioration because of restenosis. Several studies have developed the use of various kinds of spacers, plate fixation, allogeneic or autogenous bone grafting, or classical suture fixation to reconstruct a complete laminar arch. Compared with the use of autograft in existing defects, the use of spacers can shorten the operating time, reduce morbidity, and shorten postoperative neck immobilization time. Moreover, the use of autograft originating from the spinous process, iliac crest, or ribs is also associated with higher morbidity levels at the site of graft collection, higher risk of infection, bleeding, graft kickout, and more uncomfortable postoperative symptoms. ${ }^{19-23}$ Additionally, the use of a plate-only spacer is associated with hinge fusion failure because of the absence of ventral cortical bone and low adaptability to the bone tissues. ${ }^{24}$

This study reports the clinical results of the number of osteoblasts and MMP- 8 and TGF- $\beta$ modulations formed in the cervical laminoplasty using MSC-enriched scaffolds. Moreover, no previous research analyzed and studied the stem cells in a cell-based construct used in the laminoplasty procedure. The use of cell-based scaffold resulted in a higher level of mineralization and ossification compared with the use of cell-free approaches so that this technique becomes clinically advantageous in stimulating bone regeneration and healing processes. ${ }^{25-27}$ Reichert et al reported satisfactory outcomes from using stem cells in combination with scaffolds (eg, HA, demineralized bone matrix, and tricalcium phosphate [TCP]) in bone defects management. ${ }^{28}$ In spine fusion, Gan et al reported equivalent healing rates in patients using stem cells used with $\beta$-TCP scaffolds when compared


Figure 7 Hematoxylin-eosin staining to evaluate the osteoblast growth in each group. Among all groups, experimental group 3 (T3) showed more osteoblasts (black arrow). 
Table 2 Mean of Blood MMP-8 Level in Each Group

\begin{tabular}{|l|l|l|l|l|l|}
\hline \multirow{2}{*}{ Group } & \multicolumn{2}{l|}{ MMP-8 } & \multicolumn{2}{l|}{ 95\% Confidence Interval for Mean } \\
\cline { 2 - 6 } & Mean & Standard Deviation & Lower Bound & Upper Bound \\
\hline Control (C) & 112.368 & 29.34 & 80.46 & 162.32 & \\
Treatment I (TI) & $72.5 \mathrm{I}$ & 39.22 & 10.10 & 134.92 & \\
Treatment 2 (T2) & 156.28 & 49.46 & 77.58 & 234.98 & 0.194 \\
Treatment 3 (T3) & 106.53 & 56.39 & 16.79 & 196.27 & 0.001 \\
\hline
\end{tabular}

with those used with autologous grafting. ${ }^{29}$ Furthermore, similar results were reported by Neen et al who used HA scaffolds. $^{30}$

The approach used in this study was expected to support successful bone regeneration and healing following the diamond concept model. MSCs will act as progenitor cells that form new bone tissue together with the existing host cells. The presence of both osteogenic and osteoinductive properties in stem cells will contribute to both the fusion and bone union processes. ${ }^{31,32}$ The use of MSCs alone, without the presence of controlled extracellular matrix and osteoinductive factors, has been proven to decreased fusion or regeneration rates. ${ }^{33}$ The stimulation of this cellular process involving recombinant growth factors, peptides to target cellular responses and receptors, as well as small molecules (eg, Wnt signaling pathway controlling the pathway that affects bone mass), will direct progenitor cells to turn into cell lineage according to the targeted tissue. Additionally, scaffolds as a biomaterial template are osteoconductive and will provide $3 \mathrm{D}$ cues in the formation and development of tissue implantation. ${ }^{34,35}$

This is supported by the results of the present study that showed a significant difference in the average number of newly formed osteoblasts in the treatment group implanting the MSC-enriched scaffolds compared with that in the control group in which only laminoplasty alone without any grafting procedure was performed $(p<$ $0.05)$. Furthermore, the number of osteoblasts formed in this group was also higher compared with that in the group using laminoplasty with autograft implantation and laminoplasty with scaffolds without MSCs. The use of osteoblasts as osteogenesis markers is associated with the role of osteoblasts that are mononucleosis cells responsible for bone formation. These cells originated from osteoblastic precursors that are in the deeper layers of the periosteum, endosteum, bone marrow, or dura mater. The presence of more osteoblasts, in this case, is associated with the use of MSCs in groups with MSC-enriched scaffolds. ${ }^{34-36}$ This osteoblast will then produce an osteoid matrix, which is mainly composed of type I collagen.

The results of this study follow the study by Granero et al that showed a group injected with stem cells with the CMV-Cre-R26R-LacZ-MSC type having a greater growth rate and callus diameter. ${ }^{37}$ This indicates that the number of stem cells that differentiate into osteoblasts is greater when compared with that in the control group. ${ }^{27,37}$ An increase in osteoblast count in group T3 may indicate that MSC-seeded scaffolds had the best positive impact on osteogenesis compared with those in other groups. This condition also showed that MSCs play roles in new bone formation to enable a bony bridge to fill the bone defect or gap. The higher value of the osteoblast count in the treatment 2 group may explain the good osteoconductive and biocompatibility of the scaffolds used in this study so that the higher number of bone cells could grow better toward higher bone fusion rates. Tanaka et al reported the use of IP-CHA as a bone substitute in 88 patients who had

Table 3 Mean of Blood TGF- $\beta$ Level in Each Group

\begin{tabular}{|l|l|l|l|l|l|}
\hline \multirow{2}{*}{ Group } & \multicolumn{2}{|l|}{ TGF- $\boldsymbol{\beta}$} & \multicolumn{2}{l|}{$\mathbf{9 5 \% \text { Confidence Interval for Mean }}$} \\
\cline { 2 - 6 } & Mean & Standard Deviation & Lower Bound & Upper Bound \\
\hline Control (C) & 89.93 & 36.59 & 31.70 & 148.16 & 121.28 \\
Treatment I (TI) & 111.18 & 6.35 & 101.08 & 130.62 & 0.423 \\
Treatment 2 (T2) & 101.23 & 18.47 & 71.84 & 120.03 & 0.622 \\
Treatment 3 (T3) & 94.67 & 15.94 & 69.31 & 0.446 \\
\hline
\end{tabular}


Table 4 Mean of Osteoblast Count That Grew on Laminoplasty Defect

\begin{tabular}{|l|l|l|l|l|l|}
\hline \multirow{2}{*}{ Group } & \multicolumn{2}{|l|}{ Osteoblast Count } & \multicolumn{2}{l|}{ 95\% Confidence Interval for Mean } & P value \\
\cline { 2 - 6 } & Mean & Standard Deviation & Lower Bound & Upper Bound \\
\hline Control (C) & 3.75 & 1.34 & 1.52 & 5.63 & \\
Treatment I (TI) & 4.00 & 1.26 & 1.99 & 6.01 & 1.00 \\
Treatment 2 (T2) & 7.05 & 1.92 & 3.98 & 26.42 & 1.00 \\
Treatment 3 (T3) & 18.85 & 4.76 & 11.28 & 0.01 \\
\hline
\end{tabular}

expansive open-door laminoplasty. Satisfactory clinical outcomes, a fusion rate of $>95 \%$ at 1 year, preserved postoperative ROM of the cervical spine to $87 \%$, and no major complications were reported with the use of this technique. Additionally, this study also showed good bone bonding and strength results in a postoperative CT scan with high rates of bone fusion between the spacers and hinges of the laminae. ${ }^{38,39}$

Higher TGF- $\beta$ levels in the MSC-enriched scaffold group (T3) compared with those in the control group (C) were reported in the present study, although the results were not significantly different. TGF- $\beta$ is one of the cytokines in the bone matrix that plays an important role as a signal molecule in the bone regeneration process. TGF- $\beta$ will regulate migration, growth, and differentiation of MSCs or other progenitor cells. The higher TGF- $\beta$ activity is associated with the rapid recruitment of MSCs to the bone to further differentiate into osteoblasts. ${ }^{16}$ This is also supported by studies by Sun et al where the use of TGF$\beta 1$-overexpressing BMSCs results in the maximum torque, failure angle, energy failure, and torsional rigidity which are significantly higher than MSCs alone. ${ }^{17}$ However, the results of the present study in the treatment groups gave the lowest increase of TGF- $\beta$ in the mesenchymal group or treatment group 3 . This condition could be explained by the fluctuation of elevated TGF- $\beta$ levels in bone healing and regeneration. A higher increase of TGF- $\beta$ serum concentration was mainly found in the early healing periods and gradually decreased after the second week. The presence of MSCs and the already high number of osteoblasts may control and give negative feedback toward TGF- $\beta$ expression to accomplish the most ideal condition for bone regeneration. ${ }^{40}$

Concerning the significant increase in MMP-8 level in the scaffold-only groups (treatment group 2), this condition could be explained by the increase in immune response toward the presence of scaffold as a foreign object. The mean level in T3 was lower than that in T2. The MSCs may play a role in supporting the immunomodulation toward inflammatory response suppression. ${ }^{41,42}$ This condition followed the study by Mauney et al in which decreased expressions of MMP-1 and MMP-8 were found when MSCs were stimulated for osteogenic differentiation. MMP-8, which is a collagenase that plays a role in degrading collagen, will be controlled to promote the best possible ECM environment and structural conformation following osteogenic differentiation. Additionally, a decrease in MMP-8 was reported to be required in the differentiation of MSCs toward osteoblastic lineage. ${ }^{13}$ By contrast, the mean MMP- 8 value in T1 was the lowest compared with those in the other groups. In this case, autograft harvested from the body of the rabbit itself was not detected as foreign material so that minimal immune responses and minimal risk of donor rejection exist. The MMP-8 level in this group may demonstrate the primary MMP-8 response in bone regeneration and healing.

The present study has several limitations. This study has a small sample size. The groups were not followed until the fusion time and the percentage of the fusion of the grafts were investigated. Initially, MSCs were presumed to may have increased the rate of spinal fusion to 4 weeks or less compared with standard procedures in which spinal fusion was reported to be optimally investigated in 5-10 weeks. ${ }^{43,44}$ Moreover, further clinical investigations and assessments with a larger sample size would be necessary to evaluate the quality, safety, and efficacy of these new alternative substitutes. Additionally, clinical and radiological evaluation of bone fusion regarding the different number of applied MSCs with gradual follow-up time until 10 weeks are also important.

\section{Conclusion}

The use of MSC-seeded on PLA scaffolds in laminoplasty was associated with a significant decrease in MMP-8 level, 
increased TGF- $\beta$ level, and increased number of osteoblasts. MSC-seeded on PLA scaffolds could be useful to support the laminoplasty procedure to prevent restenosis. However, longer-term follow-up was required to evaluate fusion.

\section{Data Sharing Statement}

The data used to support the findings of this study are available from the authors upon request.

\section{Acknowledgments}

Irfan Fathurrahman, MD, is thanked for providing his input and expertise that significantly helped the research, especially for the support regarding research methodology and data analysis. In addition, the authors thank Enago (http://www.enago.com) for the English language review.

\section{Funding}

The authors received no financial support for the research, authorship, and/or publication of this article.

\section{Disclosure}

The authors report no conflicts of interest in this work.

\section{References}

1. Melancia JL, Francisco AF, Antunes JL. Spinal stenosis. In: Biller J, Ferro JM, editors. Handbook of Clinical Neurology. Elsevier B.V.; 2014:541-549.

2. Bagley C, Macallister M, Dosselman L, Moreno J, Aoun S, El Ahmadieh T. Current concepts and recent advances in understanding and managing lumbar spine stenosis [version 1; referees: 3 approved]. F1000Res. 2019;8:137. doi:10.12688/f1000research.16082.1

3. Fateh M, Saygi B, Karaman Ö, Bezer M. The effect of expansive open-door laminoplasty on spinal canal diameter: an experimental study on rabbits. Acta Orthop Traumatol Turc. 2013;47(2):118-121. doi:10.3944/AOTT.2013.2862

4. Kurokawa R, Kim P. Cervical laminoplasty: the history and the future. Neurol Med Chir. 2015;55(7):529-539. doi:10.2176/nmc.ra.2014-0387

5. Ratliff JK, Cooper PR. Cervical laminoplasty: a critical review. $J \quad$ Neurosurg. 2003;98(3 SUPPL.):230-238. doi:10.3171/ spi.2003.98.3.0230

6. Yu J, Xia H, Ni QQ. A three-dimensional porous hydroxyapatite nanocomposite scaffold with shape memory effect for bone tissue engineering. $J$ Mater Sci. 2018;53(7):4734-4744. doi:10.1007/ s10853-017-1807-x

7. Dhandayuthapani B, Yoshida Y, Maekawa T, Kumar DS. Polymeric scaffolds in tissue engineering application: a review. Int $J$ Polym Sci. 2011;2011:1-19. doi:10.1155/2011/290602

8. Stevens MM. Biomaterials for bone tissue engineering. Mater Today. 2008;11(5):18-25. doi:10.1016/S1369-7021(08)70086-5

9. Santoro M, Shah SR, Walker JL, Mikos AG. Poly(lactic acid) nanofibrous scaffolds for tissue engineering. Adv Drug Deliv Rev. 2016;107:206-212. doi:10.1016/j.addr.2016.04.019
10. Narayanan G, Vernekar VN, Kuyinu EL, Laurencin CT. Poly (lactic acid)-based biomaterials for orthopaedic regenerative engineering. Adv Drug Deliv Rev. 2016;107:247-276.

11. Hardy E, Fernandez-Patron C. Destroy to rebuild: the connection between bone tissue remodeling and matrix metalloproteinases. Front Physiol. 2020;11:47.

12. Almalki SG, Agrawal DK. Effects of matrix metalloproteinases on the fate of mesenchymal stem cells. Stem Cell Res Ther. 2016;7 (1):129. doi:10.1186/s13287-016-0393-1

13. Mauney J, Volloch V. Adult human bone marrow stromal cells regulate expression of their MMPs and TIMPs in differentiation type-specific manner. Matrix Biol. 2010;29(1):3-8. doi:10.1016/j. matbio.2009.09.003

14. Al-Majid A, Alassiri S, Rathnayake N, Tervahartiala T, Gieselmann DR, Sorsa T. Matrix metalloproteinase-8 as an inflammatory and prevention biomarker in periodontal and peri-implant diseases. Int J Dent. 2018;2018:7891323. doi:10.1155/2018/7891323

15. An F, Du J, Cao Y, et al. MMP8 polymorphism is associated with susceptibility to osteonecrosis of the femoral head in a Chinese Han population. Oncotarget. 2017;8(13):21561-21566. doi:10.18632/ oncotarget. 15371

16. Chen G, Deng C, Li YP. TGF- $\beta$ and BMP signaling in osteoblast differentiation and bone formation. Int J Biol Sci. 2012;8(2):272-288. doi:10.7150/ijbs.2929

17. Sun BY, Zhao BX, Zhu JY, Sun ZP, Shi YA, Huang DF. Role of TGF- $\beta 1$ expressed in bone marrow-derived mesenchymal stem cells in promoting bone formation in a rabbit femoral defect model. Int J Mol Med. 2018;42(2):897-904. doi:10.3892/ijmm.2018.3692

18. Cadena-Herrera D, Esparza-de Lara JE, Ramírez-Ibañez ND, et al. Validation of three viable-cell counting methods: manual, semi-automated, and automated. Biotechnol Rep. 2015;7:9-16. doi:10.1016/j.btre.2015.04.004

19. Hirabayashi S, Kumano K. Contact of hydroxyapatite spacers with split spinous processes in double-door laminoplasty for cervical myelopathy. J Orthop Sci. 1999;4(4):264-268. doi:10.1007/s007760050102

20. Lee JY, Hanks SE, Oxner W, Tannoury C, Donaldson WF, Kang JD. Use of small suture anchors in cervical laminoplasty to maintain canal expansion: a technical note. J Spinal Disord Tech. 2007;20 (1):33-35. doi:10.1097/01.bsd.0000211229.81930.80

21. Nakano K, Harata S, Suetsuna F, Araki T, Itoh J. Spinous process-splitting laminoplasty using hydroxyapatite spinous process spacer. Spine. 1992;17(3):S41-3. doi:10.1097/00007632-19920300100009

22. Park AE, Heller JG. Cervical laminoplasty: use of a novel titanium plate to maintain canal expansion - surgical technique. J Spinal Disord Tech. 2004;17(4):265-271. doi:10.1097/01.bsd.0000095401.27687.c0

23. Goto T, Ohata K, Takami T, et al. Hydroxyapatite laminar spacers and titanium miniplates in cervical laminoplasty. $J$ Neurosurg. 2002;97(3 Suppl):323-329. doi:10.3171/spi.2002.97.3.0323

24. Lee S, Chung CK, Kim CH. Risk factor analysis of hinge fusion failure after plate-only open-door laminoplasty. Global Spine J. 2014;5(1):9-15. doi:10.1055/s-0034-1394128

25. Bruder SP, Kraus KH, Goldberg VM, Kadiyala S. The effect of implants loaded with autologous mesenchymal stem cells on the healing of canine segmental bone defects. J Bone Joint Surg Ser A. 1998;80(7):985-996. doi:10.2106/00004623-199807000-00007

26. Kon E, Muraglia A, Corsi A, et al. Autologous bone marrow stromal cells loaded onto porous hydroxyapatite ceramic accelerate bone repair in critical-size defects of sheep long bones. J Biomed Mater Res. 2000;49(3):328-337. doi:10.1002/(SICI)1097-4636(20000305) 49:3<328::AID-JBM5>3.0.CO;2-Q

27. Ito Y, Tanaka N, Fujimoto $\mathrm{Y}$, et al. Bone formation using novel interconnected porous calcium hydroxyapatite ceramic hybridized with cultured marrow stromal stem cells derived from Green rat. J Biomed Mater Res A. 2004;69(3):454-461. doi:10.1002/jbm. a. 30014 
28. Reichert JC, Saifzadeh S, Wullschleger ME, et al. The challenge of establishing preclinical models for segmental bone defect research. Biomaterials. 2009;30(12):2149-2163. doi:10.1016/j.biomaterials. 2008.12.050

29. Gan Y, Dai K, Zhang P, Tang T, Zhu Z, Lu J. The clinical use of enriched bone marrow stem cells combined with porous beta-tricalcium phosphate in posterior spinal fusion. Biomaterials. 2008;29(29):3973-3982. doi:10.1016/j.biomaterials.2008.06.026

30. Neen D, Noyes D, Shaw M, Gwilym S, Fairlie N, Birch N. Healos and bone marrow aspirate used for lumbar spine fusion: a case controlled study comparing healos with autograft. Spine. 2006;31 (18):E636-E640. doi:10.1097/01.brs.0000232028.97590.12

31. Giannoudis PV, Einhorn TA, Marsh D. Fracture healing: the diamond concept. Injury. 2007;38(4):S3-S6. doi:10.1016/S0020-1383(08) 70003-2

32. Calori GM, Giannoudis PV. Enhancement of Fracture Healing with the Diamond Concept: The Role of the Biological Chamber. Vols. 42, Injury. Elsevier Ltd; 2011:1191-1193.

33. Abbah SA, Lam CXF, Ramruttun AK, Goh JCH, Wong HK. Fusion performance of low-dose recombinant human bone morphogenetic protein 2 and bone marrow-derived multipotent stromal cells in biodegradable scaffolds: a comparative study in a large animal model of anterior lumbar interbody fusion. Spine. 2011;36 (21):1752-1759. doi:10.1097/BRS.0b013e31822576a4

34. Robbins MA, Haudenschild DR, Wegner AM, Klineberg EO. Stem cells in spinal fusion. Global Spine J. 2017;7(8):801-810. doi:10.1177/2192568217701102

35. Chocholata P, Kulda V, Babuska V. Fabrication of scaffolds for bone-tissue regeneration. Materials. 2019;12(4):568. doi:10.3390/ ma12040568

36. Ho-Shui-Ling A, Bolander J, Rustom LE, Johnson AW, Luyten FP, Picart C. Bone regeneration strategies: engineered scaffolds, bioactive molecules and stem cells current stage and future perspectives. Biomaterials. 2018;180:143-162. doi:10.1016/j.biomaterials. 2018.07.017
37. Granero-Moltó F, Weis JA, Miga MI, et al. Regenerative effects of transplanted mesenchymal stem cells in fracture healing. Stem Cells. 2009;27(8):1887-1898. doi:10.1002/stem.103

38. Tanaka N, Nakanishi K, Kamei N, et al. Novel hybrid hydroxyapatite spacers ensure sufficient bone bonding in cervical laminoplasty. Asian Spine J. 2018;12(6):1078-1084. doi:10.31616/ asj.2018.12.6.1078

39. Tanaka N, Nakanishi K, Fujimoto Y, et al. Expansive laminoplasty for cervical myelopathy with interconnected porous calcium hydroxyapatite ceramic spacers: comparison with autogenous bone spacers. J Spinal Disord Tech. 2008;21(8):547-552. doi:10.1097/ BSD.0b013e31815c85bd

40. Maeda S, Hayashi M, Komiya S, Imamura $\mathrm{T}$, Miyazono $\mathrm{K}$. Endogenous TGF- $\beta$ signaling suppresses maturation of osteoblastic mesenchymal cells. EMBO J. 2004;23(3):552-563. doi:10.1038/sj. emboj.7600067

41. Jiang W, Xu J. Immune modulation by mesenchymal stem cells. Cell Prolif. 2020;53(1). doi:10.1111/cpr.12712

42. Qu G, Xie X, Li X, et al. Immunomodulatory function of mesenchymal stem cells: regulation and application. J Cell Immunother. 2018;4(1):1-3. doi:10.1016/j.jocit.2018.09.001

43. Virk SS, Aurand A, Bertone AL, et al. Assessment of a rabbit posterolateral spinal fusion using movement between vertebrae: a modification of the palpation exam for quantifying fusions. J Spine Surg. 2019;5(2):215-222. doi:10.21037/jss.2019.04.08

44. Ghodasra JH, Daley EL, Hsu EL, Hsu WK. Factors influencing arthrodesis rates in a rabbit posterolateral spine model with iliac crest autograft. Eur Spine J. 2014;23(2):426-434. doi:10.1007/ s00586-013-3074-0
Stem Cells and Cloning: Advances and Applications

\section{Publish your work in this journal}

Stem Cells and Cloning: Advances and Applications is an international, peer-reviewed, open access journal. Areas of interest in established and emerging concepts in stem cell research include: Embryonic cell stems; Adult stem cells; Blastocysts; Cordblood stem cells; Stem cell transformation and culture; Therapeutic cloning; Umbilical cord blood and bone marrow cells; Laboratory,

\section{Dovepress}

animal and human therapeutic studies; Philosophical and ethical issues related to stem cell research. This journal is indexed on CAS. The manuscript management system is completely online and includes a very quick and fair peer-review system, which is al easy to use. Visit http://www.dovepress.com/testimonials.php to read real quotes from published authors. 